\title{
Developing an Outcome-Based ESP Course with Blended-Learning Method for Chinese Undergraduates
}

\author{
Wanyi Du, Yu Wang \\ Foreign Language Education Centre, Kaifaqu Campus of Dalian University of Technology, Dalian, China \\ Email: wendydudu@msn.com
}

How to cite this paper: Du, W. Y., \& Wang, Y. (2019). Developing an Outcome-Based ESP Course with Blended-Learning Method for Chinese Undergraduates. Creative Education, 10, 1834-1849. https://doi.org/10.4236/ce.2019.108132

Received: July 13, 2019

Accepted: August 11, 2019

Published: August 14, 2019

Copyright $\odot 2019$ by author(s) and Scientific Research Publishing Inc. This work is licensed under the Creative Commons Attribution International License (CC BY 4.0).

http://creativecommons.org/licenses/by/4.0/

\section{(c) (i) Open Access}

\begin{abstract}
Outcome-based education is not only a talent-training mode but also a theoretical base of curriculum design. Although OBE has been widely studied and practiced around the world, few researches could be found to discuss the roles and effects of blended learning method in OBE framework. This paper develops an outcome-based ESP course with blended learning method for Chinese undergraduates who major in software engineering to acquire adequate working skills in English for the preparation of their future professions in the IT industry. It provides a comprehensive description of the course design, class practices and evaluation method. The paper also verifies the effectiveness of the course from the students' feedback, teachers' opinions and experts' evaluation.
\end{abstract}

\section{Keywords}

Outcome-Based Education, Blended Learning, ESP

\section{Introduction}

The Washington Accord was established in 1989 as an international accreditation agreement for undergraduate professional engineering academic degrees. China has become one of the signatories in 2013. Most countries in the Washington Accord adopt "outcome-based" certification standards. Since then, engineering education certification accompanied by OBE transformation has become one of the most important works in Chinese higher institutions.

CEEAA (China Engineering Education Accreditation Association) divides the ability of engineering graduates into four levels: A good understanding of engineering science fundamentals, individual ability, interpersonal communication 
ability, and engineering system perspectives. The content related to foreign language abilities is "the ability to communicate effectively on complex engineering issues with peers in the industry and the public, including writing reports and documents, presenting statements, articulating or responding to instructions, having an international perspective and being able to communicate under a cross-cultural context". This specific and targeted standard affirms the important position of working ability with a foreign language for engineers who work in an international environment.

In 2012, our school opened an ESP course targeted at students majoring in software engineering. During the teaching process, the teachers encountered the following problems: 1) students lack motivation and interest in learning; 2) teachers don't have enough understanding of the relevant professional fields and cannot play an active leading role; 3 ) insufficient input makes it hard to produce effective output, and hence the results of learning is not satisfying for both learners and instructors. In class, we tried some learner-centered activities such as "project-based learning (PBL)" (Barrows, 1996) and "cooperative learning" (May \& Doob, 1937). However, PBL can cause "cognitive load" (Sweller, 2006), not only for teachers who lack professional knowledge in the software field but also for students' learning. Meanwhile, limitations in cooperative learning such as "group hate" (Sorensen, 1981) and "unfair assessment" (Boud, Cohen, \& Sampson, 2001) can be very tricky, having an adverse impact on the evaluation of students' output.

Outcome-based education paradigm enlightened us to address the above problems. In OBE structure and system, learning output drives the entire curriculum activity and students' evaluation. OBE puts emphasis on what learners should know, understand, and demonstrate, and also focus on how to adapt learned knowledge and skills to future life roles (Killen, 2000). Based on OBE principles, we incorporated blended learning methodology in our curriculum framework, and defined our course as "outcome-based ESP". This ESP course is developed to help undergraduate students who major in computer science or software engineering enhance English working abilities in the future. From the review of literature, we found that practices of ESP courses based on OBE are rarely seen, especially within the country. Therefore, in this paper, we will give a comprehensive description of the course, including designing, implementing and evaluating processes. Meanwhile, we will take one module as an example to illustrate in details the practices and interactions between students and instructors inside and outside the classroom. Also, we will provide feedback from both students and experts in educational fields, which affirm that out-come based ESP teaching can enable learners to acquire necessary experiences and skills for their real-life scenarios in the future.

\section{Literature Review}

Outcome-based education has been advocated and practiced in educational systems around tens of countries at different levels. It has been introduced to the 
Chinese educational system since 2013. Here, we will discuss some basic theories and principles that relate to the Chinese education context and that can also be translated into our ESP instructions and learning activities.

\subsection{Definition and Two Approaches}

The most widely accepted definition of OBE around the world so far is given by Spady (1994):

Outcome-Based Education means clearly focusing and organizing everything in an educational system around what is essential for all students to be able to do successfully at the end of their learning experiences. This means starting with a clear picture of what is important for students to be able to do, then organizing the curriculum, instruction, and assessment to make sure this learning ultimately happens (Spady, 1994: p. 1).

According to the definition above, Spady also compares two common approaches in OBE practicing efforts, which he calls as traditional OBE and transitional OBE (Spady \& Marshall, 1991). Traditional OBE focuses strongly on subject-specific outcomes and some cross-discipline outcomes (such as problem-solving skills and group cooperation skills). Transitional OBE emphasizes on long-term, cross-curricular outcomes that are related closely with learners' future roles in life roles (such as being a productive worker) (Killen, 2000). Spady presented his preference to the latter approach, while in this paper, we believe that, when designing curriculum framework and learning objectives, consideration from both perspectives are necessary. Only in this case, learners can be highly motivated from both short-term accessible success and a deep understanding of long-term prospects.

\subsection{Principles of OBE and Characteristics of Outcomes}

Spady (1994) developed four principles of OBE: 1) clarity of focus; 2) designing back; 3) high expectations; 4) expanded opportunities.

This first principle means teachers must have a clear understanding of what the students will achieve in this course, and the objectives are also clearly expressed to students. All planning and teaching center on these pre-determined outcomes and all assessments also focus on these intentions. In our case, the core objective of the ESP course is to equip learners with appropriate working abilities in English in the IT field. We also divide this core objective into several major and minor objectives, which is described in detail in the "needs analysis" section.

The second principle follows the first principle, meaning that learning activity designing can be "traced back" to desired outcomes, and identifying the "building blocks" of learning that students shall achieve for the purpose of their long-term outcomes (Killen, 2000). Collier (2000) provides an application of framework design based on the "designing back" principle. Based on this principle, we design our course into hierarchical modules where students will have to 
acquire skills and experiences that are necessary for the final outcomes.

The third principle tells teachers to believe that students can complete challenging tasks. Successful outcomes promote more successful learning (Spady, 1994). Literature provides ample evidence that confidence comes from successful learning of deep knowledge and also encourages continuous deeper learning (e.g., Queensland School Reform Longitudinal Study, 1999). Therefore, setting challenging tasks that is appropriate for students' level is also a challenging task for teachers, too. To help students to complete the task, teachers also need to provide enough useful learning materials.

The last principle is based on the idea that not all students will learn the same thing at the same time in the same way (Spady, 1994). Outcomes shall be designed to promote more effective learning at all levels (Driscoll \& Wood, 2007). In view of this, it is the responsibility of teachers and curriculum designers to look for task-based resources and provide guidance for students at different levels in the institution.

Beyond taking Spady's four principles into full consideration, we also adopt the characteristics of outcomes defined by Williams et al. (1999) when designing the course. Standards that the course will meet include: 1) "achievable and assessable" tasks; 2) "transparent" goals and process; 3) "fair" evaluation that will "reflect results of learning".

\subsection{OBE with Blended Learning}

Blended learning is increasingly becoming an effective part of an integrated academic curriculum (Diaz \& Cartnal, 2000; Ross, 2001; Allen et al., 2007). Whereas, studies on outcome-based blended learning are rare. In one of the few studies, V. Ross (2001) conducted qualitative research and reports inadequate preparation from faculty members because of their lack of confidence in the grasp of technology and inexperience of online guidance. The reported hindrance is, on the contrary, a priority in our institution where, with all students majoring in computer science and engineering, both learners and instructors are well equipped with technology capabilities. Therefore, it is possible to carry out a deeper and more comprehensive review of the effectiveness of blended learning under the framework of OBE.

\section{The Course Design}

In this section, we will illustrate in details how we design the course, starting from analyzing course objectives, setting up output tasks to visualizing tasks through driving maps. For each of the steps, we adopted principles and characteristics of OBE as mentioned in former section. When studying on the course objectives, we take the principles of "clarity of focus" and "designing back" into consideration. Then, to achieve the characteristic of "achievable and accessible", we designed progressive task chains and visualized the task chains through flow charts that we call "driving maps" to express the correlations between required 
communication capabilities for the learners' "future role" and the established output tasks.

\subsection{Course Objectives Based on Need Analysis}

Because OBE follows the principle of "designing back", the first step of course design shall be clarity of outcomes. Outcomes of an ESP course shall come from experiences and skills that will satisfy learners' future needs. Designing processes concerning this ESP course include: needs analysis-the decision on teaching objectives-construction of situational output tasks-visualize tasks through task chains (Figure 1). For the purpose of this, our research team first conducted needs analysis through questionnaire surveys, interviews with graduates, teachers entering software enterprises to understand the needs of the IT industry on the perspective of English working abilities. Proper needs analysis helps us correlates potential outcomes with clear teaching objectives and learning outputs. These objectives also guided us to design output tasks that would motivate students to look for appropriate learning materials to related gain knowledge and skills. The situational simulation tasks fully embody language and industry characteristics of the ESP curriculum.

\subsection{Progressive and Accessible Task Chains}

Task chains firstly make students to have a global understanding of language capabilities within the industry, but they are often difficult to start with. Then tasks are decomposed into a series of progressive and accessible chains that are listed from simple to difficult, from peripheral to the core, from replication of language to the creative use of language (Nunan, 2004). Progressive and accessible task chains guide students to "integrate existing knowledge and new knowledge into a knowledge network to help students finally achieve higher communication skills" (Hutchinson \& Waters, 1987).

In our course, "English for IT professionals", we decomposed the final outcome into a four-module \& three-layer task chain (Figure 2). The four modules are 1) history and milestone of IT industry with a module task of simulation forum on IT industry; 2) working process of IT industry with a module task of making a competitive produce analysis report; 3) communication skills in IT

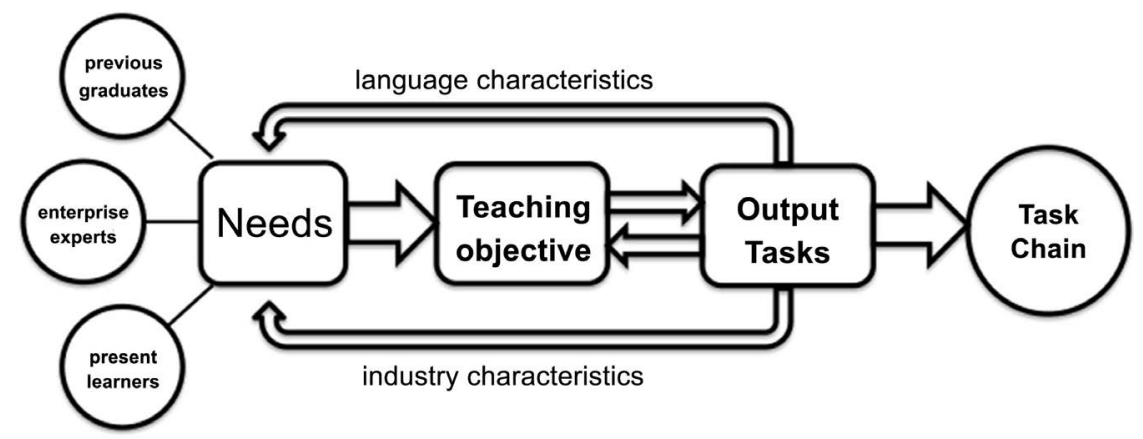

Figure 1. Designing process of the ESP course- "English for IT professionals". 


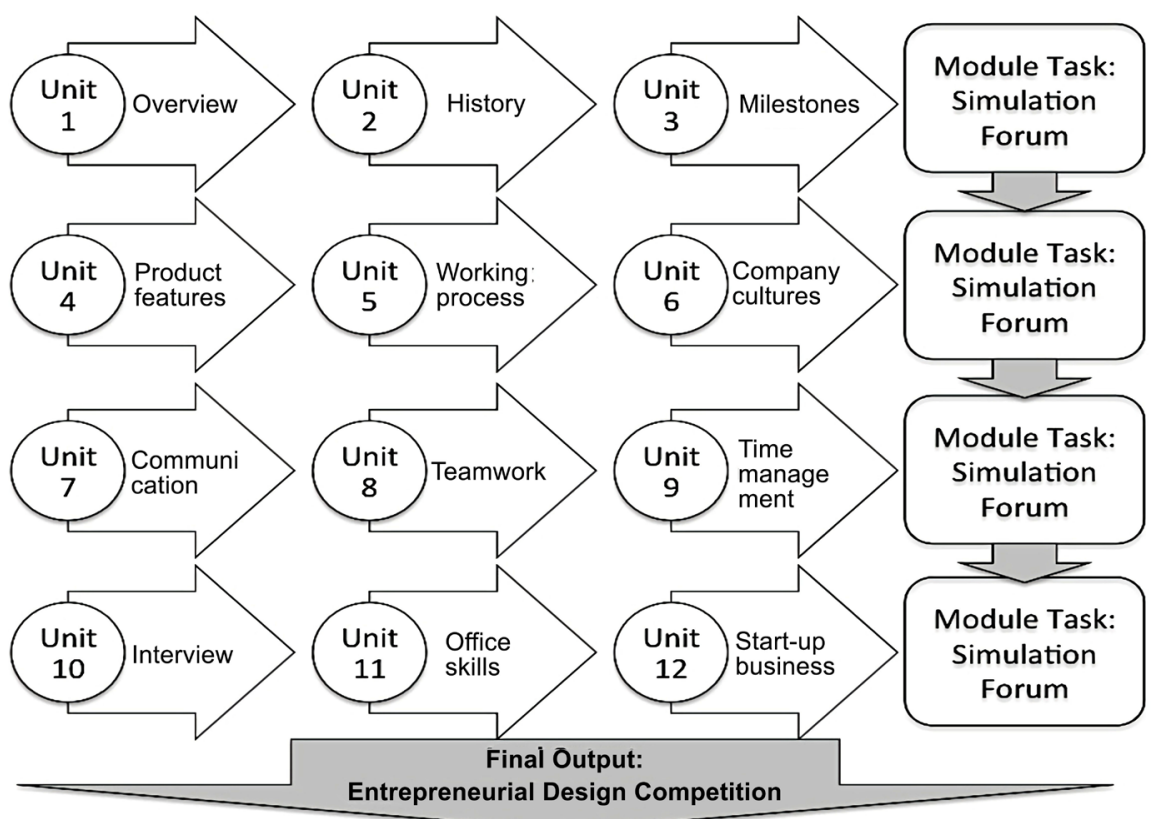

Figure 2. Task chains of the course.

industry with a module task of simulating product delivery conference; 4) surviving in the office with a module task of mock interview. Three-layer task chain refers to "unit-driven", "module-driven", and "course-driven", which means content and skills acquired in all situational tasks from each unit are to pave ways for module task, and the outputs of the previous module are preparations for the next module, and outputs of the four module tasks are for students to get ready for the final situational task-an entrepreneurial design competition, thereby forming an overall and progressive task chain. Task chains reflect the professionalism, continuity and integrity of curriculum design, helping the learners to complete the internalization of knowledge and achieve the goals of out-come based ESP class.

\section{3. “Driving Maps” to Visualize Tasks}

Task visualization is a strong supporting tool to help learners construct a framework of skills, and is a significant step in the course design of the OBE curriculum. Visualized driving maps (Figure 2 \& Figure 3) make outcomes "transparent", so the learners can evaluate on their own whether the outcomes are "achievable" and how difficult those tasks are according to their own knowledge level.

Driving maps also conform to the learning and thinking habits of engineering students. By helping students to record the results of each stage of work in the form of charts and maps, they will have a thorough understanding of the industry process. The functions of the task flow chart are mentioned in Kirschner et al. (2015), which are to help learners be aware of the tasks at each stage, the problems that need to be solved, and concepts need to be learned, and hence, to effectively improve learning efficiency. 


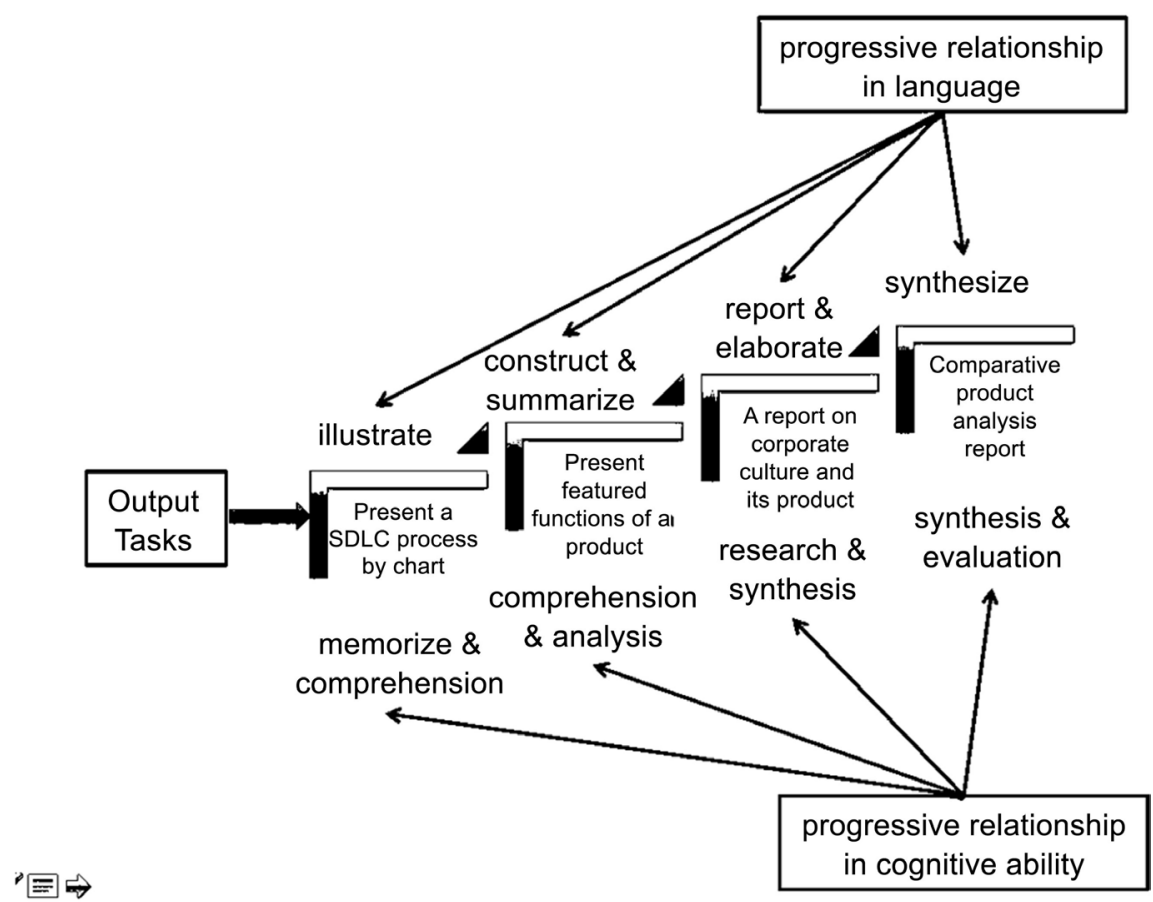

Figure 3. Task driving maps of module two, illustrating progressive relationships both in language skills and cognitive abilities.

\section{Case Study}

In this part, we will use one module of the course as an example to illustrate in detail how we practice of OBE in our ESP course through step by step motivation, enabling learners at different levels and a combination of online and offline assessments.

\subsection{Step by Step Motivation}

OBE emphasizes preparing students for their future roles. To better motivate the students to get ready for the tasks, all communication scenarios and discussion topics come from real cases they may encounter in their future study and work. Before the module study, it is the teachers' job to let students recognize the gap between skills needed for the tasks and their own levels of knowledge. Teachers also need to make sure the tasks are with real communicative value and are progressively located in the framework, and that students will complete the task from simple to difficult, from the periphery to the core.

In the module of "English for IT professionals", students will be able to talk about the working processes, product features and company cultures in English. As is shown in Figure 3, the output task of module two is a presentation on comparative product analysis (CPA). To acquire skills and knowledge that are necessary for the output, three unit tasks also present a progressive relationship. Language skills range from illustration to construction in order to improve communication skills. Content of the learning materials starts from software development processes to final product release presentation, laying emphasis on 
teamwork and problem analysis.

Tasks are designed and linked to meet the six cognitive levels proposed by Bloom (1956), from the low-level ability of memorizing and understanding of the high-level ability of surveying, analyzing, and evaluation. From a linguistic point of view, students also exercise different language skills at different stages of learning, starting from illustrating to reporting and elaboration (see Figure 3). The final module task, CPA, is actually to synthesize outcomes from the previous three units, including a general description of the product, showing the outstanding features of the product, comparing the strengths and weaknesses of each product horizontally (functions and features) and vertically (enterprise culture and philosophy) and presenting opinions on relationships between design and product development.

Visualized driving maps are not enough to help students locate their own position in this knowledge framework. Therefore, the last step of motivation is to present a real-life scenario in class. In module two, the teacher showed students a video clip about Google's annual product release conference, and then invited some groups to try to demonstrate some product features in front of the whole class. Other groups then carried out a discussion on the advantages and disadvantages of the output results, and proposed constructive revisions. In this process, students discovered their own learning gaps, for example, being unfamiliar with technical terms, using too complicated language structures, and having no impressive keywords in descriptions. In the end, the teacher and the students could categorize these inefficiencies as either a lack of industry-related language knowledge or an ignorant of effective communicative principles. In this way, teachers could guide students to conduct targeted learning based on their own gaps, but do not push them to aimless passive learning.

\subsection{Enabling Learners at Different Levels}

According to the literature of cognitive psychology, when learners are allowed to seek their own interest, their motivation to learn grows, subsequently leading to a heightened attention level (Bandura, 1982; Chaffee \& Schleuder, 1986). Even within the same institution, learners' levels are different. In the past, conduct selective learning is difficult in the traditional classroom environment, especially when teachers are facing a large number of learners with limited teaching time. While the advent of the Internet and online learning technology make it possible for learners to make learning processes adapt to their own needs and interests.

To enable learners at different levels to achieve task goals, teachers need to provide appropriate input materials so that learners can select "useful parts for deep processing, practicing, and memorizing" to optimize learning outcomes (Wen, 2015). In our ESP course, teachers selectively prepared learning materials at different levels after a discussion with professors who teach specialized courses and experts from the IT industry. All learning materials are labeled as "basic", "intermediary", and "advanced" and are uploaded to our online learning 
platform where students can choose according to their own interests. This ensures the availability and accessibility of the input learning materials (Kumaravadivelu, 2006).

Take unit 5 "Features of IT Product" as an example. The basic learning material requires students to master some technical terms used to describe the general functions and characteristics of the software, such as "Expandability", "Automation", "Interface", "touch screen", etc. Intermediate learning material is a short video entitled "Six best accounting soft wares". Students were asked to discuss the common features of the same type of software after studying online and also present their answers in the classroom. Advanced learning materials include an analytical article from Harvard Business School named "Apple's Secret-It Tells Us What We Should Love" and a video about "Google annual product release conference". Students learned about state-of-the-art concepts on software design and ways of displaying product features, from the perspective of language forms and discourse structures. The selected learning materials in other units of the second module are listed in Table 1, which are also arranged progressively from the basics to the more advanced for learners at different levels to learn selectively.

After providing supporting materials at different levels, teachers would further encourage the completion of tasks in classroom activities. Classroom activities are also a reflection of the progressive method in respective to the online materials. In the early stage of a class hour, the major activity is repetition on terms

Table 1. Selected learning materials of module two and their correlations with output tasks.

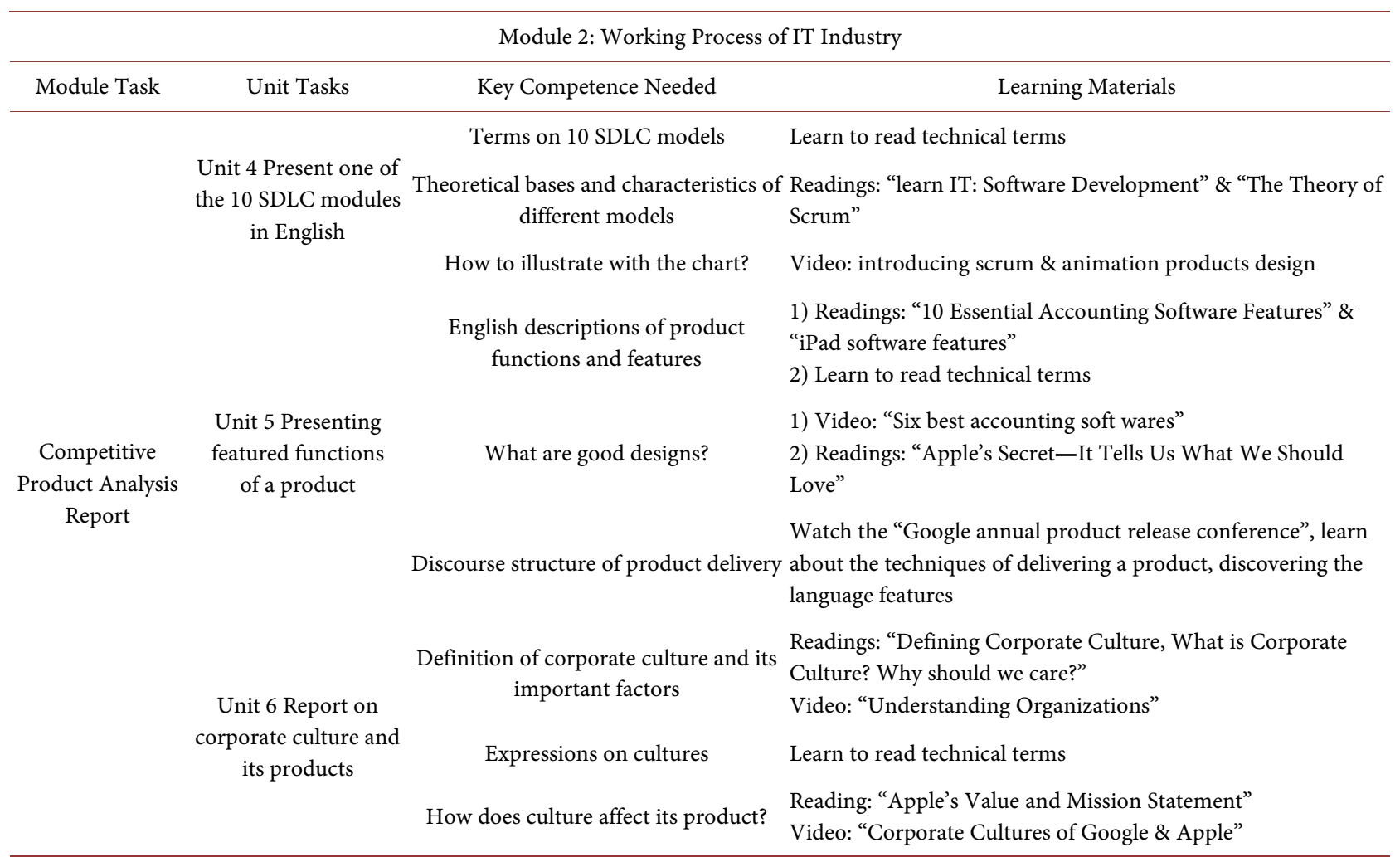


and concepts, taking forms of braining storming, translation or explanation. Following a recalling of important terms, students can continue on with the intermediary level of activities such as comprehension questions, group discussions and reporting, and role-play. Advanced level of activity takes the form of synthesizing report writing online and meanwhile, a presentation in the classroom. The activities of the advanced stage pay more attention to the output of the language paradigm and the application of analysis, summarization and comprehensive evaluation capabilities.

Let's look at Unit 5 again, in the basic learning phase, reviewing of concepts and terminology was facilitated through brainstorming and questioning. The intermediate level was a group discussion. The teacher prompted the students to notice the special classification of the product features in the reading material, namely "core features", "indispensable features" and "market gimmicks". Next, the teacher distributed the worksheet, asking the team to categorize the different product characteristics and then give reasons. The teacher summarized the same and different opinions from the students based on their report. This activity not only consolidates relevant terminology but also motivates students to think. The advanced task was a discourse analysis and presentation. Students had previously watched the "Google's Annual Product Release Conference" online, having laid a foundation of form and language support. In the classroom, teachers inspired thinking through questions, such as, "What are the products presented?" "What are the features of the product?" "What language structure does the speaker use to display these product features?" With these questions, students firstly identified the terms related to product features, such as "interface", "UI", "voice control", etc. Then they discovered different adjectives and terms to describe the characteristics of the product, such as "beautiful interface", "automatic control". The third step was to analyze discourse structures when delivering a product. The following principles are the outcomes of the teacher and students' discussion: 1) Begins the sentence with first person "I" or "We"; 2) Each paragraph has a topic sentence; 3 ) Introduces a product as telling a story; 4) Repeat key information. Finally, the teacher invited one or two groups to make a demonstration and other groups can observe and learn. Teachers would offer a final summary at the end of the class, clarifying what they have acquired and its relationships with the output of module tasks.

\subsection{Online and Offline Assessment}

The most important feature of outcomes-based education is that all students are expected to be successful (Killen, 2000). It also means that assessment of learning outcomes emphasize how well the learners have demonstrated rather than on how much (Biggs \& Collis, 1982). Meanwhile, it refers that all learners shall have multiple choices to show their outcomes but not a single chance at the end. Therefore, as the last part of our ESP course, the evaluation does not occur at the end of the learning process, but rather happens during the enabling process. We 
offer different methods of assessment at different stages of learning. The whole evaluation process is a combination of instant-evaluation (i.e., when learning occurs) and delay-evaluation (after learning completion) (Wen, 2015) so that assessment becomes part of motivated learning. On the other hand, students of G-generation rely much more on the power of the Internet and expect objective and timely feedback even more than those of past generations. They attach great importance to peer evaluation. Taking the above into consideration, our assessment is also a combination of online peer-to-peer evaluation and offline teacher-student cooperative evaluation. In this way, students can receive feedback from multiple channels, taste success or failure in time and constantly adapt their own ways of learning to achieve the ultimate outcome.

As seen in Table 2, all stages of learning have a corresponding evaluation method. The review tasks (i.e. term reading recording) are mainly set for the primary learning content. The transformative tasks (i.e. online discussion) are designed for intermediate and advanced levels of study. Evaluation methods are corresponding to the output difficulties, from simple peer scoring to more complicated teacher-student cooperative evaluation.

Preparing a comprehensive and detailed evaluation specification is of great significance for our module-based online and offline evaluation. When this had been done, a descriptive requirement (Table 3) was shown to the students along with the visualized driving map. The teacher and students discussed on the possibility and difficulties together. Sometimes, the teacher would also show students some samples. For example, in unit four, "software development process", the teacher played a video on waterfall development and then discussed on how to use a flow chart to illustrate the working procedure. With a standardized sample, students could easily compare their own outcomes and make efforts to complete the task better.

In OBE, assessment is based on outcomes that come from the pre-determined

Table 2. Evaluation method at different stages of learning, using unit 4 as an example.

\begin{tabular}{|c|c|c|c|c|c|}
\hline Content & $\begin{array}{l}\text { Stages of } \\
\text { learning }\end{array}$ & Online/offline & Assignments & Types & Ways \\
\hline \multirow{3}{*}{$\begin{array}{c}\text { Grasp of } \\
\text { technical terms } \\
\text { (Basic) }\end{array}$} & before-class & online & $\begin{array}{l}\text { recording of } \\
\text { term reading }\end{array}$ & delayed & peer-assessment \\
\hline & in-class & offline & oral explanation & instant & teacher evaluation \\
\hline & in-class & offline & quiz & delayed & teacher evaluation \\
\hline \multirow{3}{*}{$\begin{array}{l}\text { Discussion on } \\
\text { good design } \\
\text { (Intermediate) }\end{array}$} & before-class & online & $\begin{array}{c}\text { online } \\
\text { discussion }\end{array}$ & delayed & $\begin{array}{l}\text { peer-assessment \& } \\
\text { teacher evaluation }\end{array}$ \\
\hline & in-class & offline & $\begin{array}{l}\text { worksheet and } \\
\text { discussion }\end{array}$ & instant & $\begin{array}{l}\text { group assessment \& } \\
\text { teacher evaluation }\end{array}$ \\
\hline & after-class & online & written report & delayed & $\begin{array}{l}\text { peer-assessment \& } \\
\text { teacher evaluation }\end{array}$ \\
\hline $\begin{array}{l}\text { Presentation of } \\
\text { product features } \\
\text { (Advanced) }\end{array}$ & in-class & offline & presentation & instant & $\begin{array}{c}\text { Teacher \& students } \\
\text { collaborative evaluation }\end{array}$ \\
\hline
\end{tabular}


Table 3. Detailed specifications on tasks and requirements of module 2.

\begin{tabular}{|c|c|c|c|c|}
\hline \multicolumn{5}{|c|}{$\begin{array}{l}\text { Tasks for Module Two } \\
\text { "Features of the IT Industry" }\end{array}$} \\
\hline & Task of Unit 4 & Task of Unit 5 & Task of Unit 6 & Module Task (CPA) \\
\hline Description & $\begin{array}{l}\text { Presentation on } 10 \text { SDLC } \\
\text { models }\end{array}$ & $\begin{array}{l}\text { Simulation of Product } \\
\text { Release Conference }\end{array}$ & $\begin{array}{l}\text { Analysis of IT Corporate } \\
\text { Cultures }\end{array}$ & Competitive Products Analysis \\
\hline Requirements & $\begin{array}{l}\text { 1) Prepare a 5-mins } \\
\text { presentation describing } \\
\text { one SDLC model. } \\
\text { 2) Using graphs and charts } \\
\text { as visual aids. } \\
\text { 3) Work with your group } \\
\text { members. }\end{array}$ & $\begin{array}{l}\text { 1) Prepare a } 10 \text {-mins } \\
\text { presentation introducing a } \\
\text { new IT product. } \\
\text { 2) Stress the core features of } \\
\text { the product. } \\
\text { 3) Each group member } \\
\text { present one key feature. }\end{array}$ & $\begin{array}{l}\text { 1) Prepare a 10-mins } \\
\text { presentation on Corporate } \\
\text { Culture Analysis. } \\
\text { 2) Research on the corporate } \\
\text { culture of one IT company from } \\
\text { five aspects. } \\
\text { 3) Group collaboration. }\end{array}$ & $\begin{array}{l}\text { 1) Prepare a } 15 \text {-mins } \\
\text { presentation on product analysis. } \\
\text { 2) Compare and contrast } 3 \\
\text { brands of one type of IT product. } \\
\text { 3) Discuss on good designs. } \\
\text { 4) Come up with your own } \\
\text { opinions on IT product design } \\
\text { and development. }\end{array}$ \\
\hline Assessment & $\begin{array}{l}\text { 1) Clear and fluent } \\
\text { description of the SDLC } \\
\text { model. } \\
\text { 2) Proper use of } \\
\text { professional terms. } \\
\text { 3) Charts and graphs are } \\
\text { clear and well designed. }\end{array}$ & $\begin{array}{l}\text { 1) Clear and fluent } \\
\text { description of product } \\
\text { features. } \\
\text { 2) Proper use of professional } \\
\text { terms and language patterns. } \\
\text { 3) Core features of a product } \\
\text { can be demonstrated lively. }\end{array}$ & $\begin{array}{l}\text { 1) Clear and fluent description of } \\
\text { the organization and its culture. } \\
\text { 2) Proper use of professional terms. } \\
\text { 3) Can relate corporate culture with } \\
\text { its products. }\end{array}$ & $\begin{array}{l}\text { 1) Clear and fluent description of } \\
\text { product features and functions. } \\
\text { 2) Analysis is logical and } \\
\text { convincing. } \\
\text { 3) Presentation skills are well } \\
\text { demonstrated. } \\
\text { 4) Good group cooperation and } \\
\text { collaboration. }\end{array}$ \\
\hline $\begin{array}{l}\text { Professional } \\
\text { Knowledge \& } \\
\text { Skills }\end{array}$ & $\begin{array}{l}\text { Be familiar with the } \\
\text { concept of SDLC and } 10 \\
\text { SDLC models. }\end{array}$ & $\begin{array}{l}\text { Get to know different types } \\
\text { of product features. }\end{array}$ & $\begin{array}{l}\text { Get to know the concept of } \\
\text { corporate culture and different } \\
\text { types of cultures. } \\
\text { Understand how to research on an } \\
\text { organization through its website. }\end{array}$ & $\begin{array}{l}\text { Combination knowledge and } \\
\text { skills from unit } 4 \text { to unit } 6 \text {. }\end{array}$ \\
\hline $\begin{array}{l}\text { Communicative } \\
\text { Skills }\end{array}$ & $\begin{array}{l}\text { Describing process with } \\
\text { chart and graphs. }\end{array}$ & $\begin{array}{l}\text { Express product features in } \\
\text { English. } \\
\text { Understand language } \\
\text { patterns when presenting a } \\
\text { product. }\end{array}$ & $\begin{array}{l}\text { Terms used to express corporate } \\
\text { culture. } \\
\text { Be able to talk about positive and } \\
\text { negative corporate cultures. }\end{array}$ & $\begin{array}{l}\text { Combination knowledge and } \\
\text { skills from unit } 4 \text { to unit } 6 \text {. }\end{array}$ \\
\hline
\end{tabular}

key competencies that conform to CEEA requirements. Beside this, our evaluation criteria are also based on cooperation with the experts in the IT industry. As is shown in Table 3, the criteria highlight and increase the proportion of teamwork as well as the ability to read and write working documents. Another prominent feature is that it covers the "speech and non-verbal communication skills needed to solve complex problems" in the teaching objectives. In this way, we make sure that the assessments "take into account the context in which outcomes should be demonstrated” (Vickery, 1988).

As illustrated above, all learners are offered enough learning opportunities and could acquire appropriate learning results through multiple cycles of motivating, enabling and assessing. Blended learning also allows the learners to adapt to their own level of learning by choosing their own allocations within the group and make decisions on their own schedule.

\section{Feedbacks of the Course}

After two rounds of practice, our outcome-based ESP course received good 
feedbacks from the perspectives of students, teachers and curriculum design experts.

\subsection{Students' Feedback}

Surveys were conducted through questionnaires and open-question interviews. Students were asked to reflect on the aspects of curriculum design, learning process, material input, and task output. The following are some feedbacks:

1) Description on the teaching method

"The visualized drive map not only gives us an overall understanding of the course, but also the English working abilities incorporated in each unit and module. Meanwhile, the simulation tasks based on real working context such as the simulated industry forums, product release conference, and the mock are good practices and preparations before we enter the industry, so we can feel a real need to do it well."

2) Description on the content and learning material

"The course is not only about language abilities but also pays attention to communication skills, problem-solving skills and teamwork ability. For example, we learned about the concept of teamwork through online learning, and then we practiced teamwork through simulation tasks. We encountered the same problems mentioned in the reading material and actually tried some of the solutions offered in the resources. And we could know what methods are useful for us."

3) Description on teachers' role

"Teachers' role is important in blended learning. Teachers help us understand the tasks, maintaining the interest in learning, offer help in frustration. The output tasks are motivations for students to participate in online learning on time, and teachers could regulating our Language in class, making sure the output is effective."

The above responses are not only a reflection of learners' affirmation on the framework and content of the course but also revealing evidence that students have achieved the predetermined objectives of the course, which emphasize on the indicators of English working abilities, such as communication, cooperation and problem-solving skills in IT industry.

\subsection{Teachers' Opinions}

From the perspective of teachers, the outcome-based ESP course effectively solved the problem of learners' lacking motivations by stimulation of different tasks, and the abundant online resources provided learners enough input to ensure efficient output. Meanwhile, OBE also motivated instructors to reverse the teaching and learning process, and challenged instructors not only on how well they understand the whole new theory of teaching but also on their ability to absorb professional knowledge in IT field. The following are some positive reflections from the teachers:

OBE framework has promoted the transformation of teachers' role from a 
passive lecturer to a learning facilitator.

Output-oriented curriculum design makes connections among the content clear, and there are specific rules in teaching design. Not only the teaching effect is greatly improved, but also the learning effect is maximized (Wen, 2016). OBE improved the professionalism of ESP classrooms, student satisfaction, promoted teaching and learning, and also promoted teachers' satisfaction well-being, so that more enthusiasm is invested in teaching, forming a virtuous circle of "teaching" and "learning".

The evaluation process is important in OBE so that teachers can understand the effectiveness and pertinence of their guidance. The classroom assessment helps teachers to continuously obtain feedback information so that teachers could target improvements in teaching content and methods, and hence could facilitate iterative updates of the curriculum.

\subsection{Experts' Evaluation}

After one year of evaluation from the selective board of experts from the school, our ESP course was finally honored as one of the excellent courses in the year 2018. The following are the opinions from experts:

1) Students were fully mobilized. There were a high-degree of class participation and a high-degree of learning efficiency. Teachers played well a guiding role in and outside the class.

2) The design of curriculum satisfied the needs of contemporary college students in content, methods, and practice activities.

3) It was a successful transformation from traditional university English class to out-come based ESP, which shall continue in the future.

According to the positive feedbacks from students, teachers and experts, we can say that incorporated blended learning method into out-come based ESP course is a successful solution to resolve problems existing in traditional classroom, such as lacking motivation, insufficient input and difficulty of the positioning of English instructors.

\section{Pedagogical Implications}

In this paper, we discussed how we developed an ESP course, following the principles and characteristics of OBE. In class practices, we took blended learning methodology to promote autonomous learning and sufficient input to make sure of effective output.

In the continuous teaching practices, we also encountered some problems, such as malicious online peer-assessment, learning material being out of date because of the amazing speed of technology innovation and hence, the pressure of updating the content for language teachers. Through summarization and reflection, we will improve the curriculum framework in future from the following aspects: 1) improving the reliability and validity of online evaluation through more detailed assessing specifications and training of student assistants; 2) en- 
suring the timeliness, variety and practicability of learning materials; 3) promoting personal growth of the teachers as well as their communication and cooperation abilities, constructing a teaching community of teachers, experts and specialized professors.

\section{Conflicts of Interest}

The authors declare no conflicts of interest regarding the publication of this paper.

\section{References}

Allen, E., Seaman, J., \& Garrett, R. (2007). Blending in: The Extent and Promise of Blended Education in the United States. Needham, MA: Sloan Consortium.

Bandura, A. (1982). Self-Efficacy Mechanism in Human Agency. American Psychologist, 37, 122-147. https://doi.org/10.1037/0003-066X.37.2.122

Barrows, H. S. (1996). Problem-Based Learning in Medicine and Beyond: A Brief Overview. New Directions for Teaching and Learning, No. 68, 3-12. https://doi.org/10.1002/tl.37219966804

Biggs, J. B., \& Collis, K. F. (1982). Evaluating the Quality of Learning: The SOLO Taxonomy (Structure of the Observed Learning Outcome). New York: Academic Press.

Bloom, B. (1956). Taxonomy of Educational Objectives: The Classification of Educational Goals. Book 1: Cognitive Domain, London: Longman.

Boud, Cohen, \& Sampson (2001). Peer Learning in Higher Education: Learning from and with Each Other.

Chaffee, S. H., \& Schleuder, J. (1986). Measurement and Effects of Attention to Media News. Human Communication Research, 13, 76-107. https://doi.org/10.1111/j.1468-2958.1986.tb00096.x

Collier, D. (2000). Assessment Based on Outcomes of Significance. In Annual Conference of the Association for the Study of Evaluation in Education in Southern Africa. Port Elizabeth, South Africa, 26-29 September 2000.

Diaz, D., \& Cartnal, R. (2000). Students' Learning Styles in Two Classes. College Teaching 47, 130-136. https://doi.org/10.1080/87567559909595802

Driscoll, A., \& Wood, S. (2007). Developing Outcomes-Based Assessment for Learner-Centered Education: A Faculty Introduction. Sterling, VA: Stylus Publishing, LLC.

Hutchinson, T., \& Waters, A. (1987). English for Specific Purposes. Cambridge: Cambridge University Press. https://doi.org/10.1017/CBO9780511733031

Killen, R. (2000). Outcomes-Based Education: Principles and Possibilities.

Kirschner, P. A., Sweller, J., \& Clark, R. E. (2015). Why Minimal Guidance during Instruction Does Not Work: An Analysis of the Failure of Constructivist, Discovery, Problem-Based, Experiential, and Inquiry-Based Teaching. Educational Psychologist, 41, 75-86. https://doi.org/10.1207/s15326985ep4102_1

Kumaravadivelu, B. (2006). Understanding Language Teaching: From Method to Post method. New York, London: Routledge. https://doi.org/10.4324/9781410615725

May, M., \& Doob, L. (1937). Cooperation and Competition. New York: Social Sciences Research Council.

Nunan, D. (2004). Task-Based Language Teaching. Cambridge: Cambridge University Press. https://doi.org/10.1017/CBO9780511667336 
Ross, V. (2001). Offline to Online Curriculum. Journal of Distance Learning Administration, State University of West Georgia, 4, 1-4.

Sorensen (1981). Grouphate: A Negative Reaction to Group Work. Washington DC: International Communication Association.

Spady, W. D. (1994). Outcomes Based Education: Critical Issues and Answers. Arlington, VA: American Association of School Administration.

Spady, W. D., \& Marshall, K. G. (1991). Beyond Traditional Outcomes-Based Education. Educational Leadership, 49, 67-72.

Sweller, J. (2006). The Worked Example Effect and Human Cognition. Learning and Instruction, 16, 165-169. https://doi.org/10.1016/j.learninstruc.2006.02.005

Vickery, T. R. (1988). Learning from an Outcomes-Driven School District. Educational Leadership, 45, 52-56.

Wen, Q. (2015). Developing a Theoretical System of Production-Oriented Approach in Language Teaching. Foreign Language Teaching and Research, 4, 547-558.

Wen, Q. (2016). Teacher-Student Collaborative Assessment (TSCA): A New Method of Assessment to Production-Oriented Approach. Foreign Language World, No. 5, 37-43.

Williams, D., Johnson, B., Peters, J., \& Cormack, P. (1999). Assessment: From Standardised to Authentic Approaches. In B. Johnson, \& A. Reid (Eds.), Contesting the Curriculum (pp. 146-160). Katoomba: Social Science Press. 